\title{
ARTÍCULOS
}

\section{SUBJETIVIDAD O MIEDO. LOS MODOS DE SER Y HACER DE LAS BRUJAS EN LOS ANDES}

\author{
SUBJETIVITY AND FEAR. THE WAYS OF BEING AND DOING OF WITCHES IN \\ THE ANDES
}

\section{Óscar Muñoz Morán ${ }^{1}$}

Universidad Complutense de Madrid

Recibido: 15 de mayo de 2020; Aprobado: 1 de octubre de 2020.

Cómo citar este artículo / Citation: Muñoz Morán, Óscar. 2021. "Subjetividad o miedo. Los modos de ser y hacer de las brujas en los Andes". Disparidades. Revista de Antropología 76(2): e028. doi: <https://doi.org/10.3989/dra.2021.028>.

RESUMEN: En este artículo me gustaría proponer un nuevo acercamiento a la figura de las brujas y sus modos de actuar en los Andes. Al mismo tiempo, utilizo la percepción que de estos personajes se tiene para plantear un modelo de análisis de la noción de miedo en los Andes. Lo que sugiero es que en la comunidad quechua hablante de Coipasi las brujas son reconocidas como sujetos y, por tanto, queda normalizada la relación que con ellas se pueda tener. Así, el miedo no aparece como factor de esta relación.

PALABRAS CLAVES: Brujería; Miedo; Subjetividad; Fluidez.

ABSTRACT: I intend in this article to propose a new approach to witches and their ways of doing in the Andes. At the same time, I use the perception that this has to propose a model of analysis of the notion of fear in the Andes. What I suggest is that in the Quechua-speaking community of Coipasi, witches are recognized as subjects and, therefore, the relationship that one may have with them is normalized. So, fear does not appear as a factor in this relationship.

KEYWORDS: Witchcraft; Fear; Subjectivity; Fluidity.

Copyright: @ 2021 CSIC. Este es un artículo de acceso abierto distribuido bajo los términos de la licencia de uso y distribución Creative Commons Reconocimiento 4.0 Internacional (CC BY 4.0).

1 Correo electrónico: oscarmun@ucm.es. ORCID iD: <https://orcid.org/0000-0002-0944-2687>. 


\section{INTRODUCCIÓN}

En noviembre de 2011 en unas extrañas circunstancias en las que están implicados unos "rateros peruanos», el Tío y la ciudad de Potosí, sufrí un robo que, entre otros objetos, me dejó sin mi ordenador personal. En él se encontraban las grabaciones que durante el mes anterior había realizado en mi trabajo de campo en la cercana comunidad quechua hablante de Coipasi². Gracias a un técnico de sonido conseguí recuperar de mi grabadora los archivos de la semana anterior. Todos menos uno: la entrevista realizada a doña Dionisia, quien, según consenso comunario, es la bruja de la comunidad $^{3}$. A nadie en el pueblo pareció extrañarle esta circunstancia, pues como me dijo don Vicente «eso siempre es así». Esa entrevista con doña Dionisia fue diferente a las demás que había tenido, ya que ella solo hablaba quechua y, por tanto, la conversación se llevó a cabo con un traductor. Por otro lado, doña Dionisia que vivía en una pequeña casa alrededor de la cual tenía cultivadas plantas medicinales, estuvo en todo momento moviéndose de un lugar a otro, de tal forma que no me permitió apenas tomar notas. Lo poco que he podido rescatar de esa entrevista (pues también perdí mi diario de campo) es lo que conseguí recordar al día siguiente al robo.

Desde que esto sucedió, la figura de la única bruja de la comunidad me ha causado cierta curiosidad. Aunque muy pocas veces pregunté expresamente por ella, su nombre aparecía con frecuencia en las conversaciones que he tenido en la comunidad desde entonces. Su presencia era la excusa perfecta para que me hablaran de brujería, algo que, para mi sorpresa, estaba más presente en la cotidianidad del lugar de lo que la literatura suele mencionar. Es decir, la brujería es evidente que no es algo de lo que los coipaseños hablen a diario, pero tampoco parecen esconderlo y no aparenta ser un tema tabú ni, como mostraré en este texto, algo a lo que se tema especialmente.

2 Coipasi es una pequeña comunidad quechua hablante que se encuentra en el municipio de Chaquí. Coipasi es la cabecera del ayllu del mismo nombre y sus habitantes se dedican principalmente a la agricultura complementado con algo de ganadería. No obstante, la mayor parte de su población joven (entre los 20 y los 40 años ha emigrado a las ciudades cercanas incluso a otros países, principalmente Argentina).

3 El nombre es ficticio. He decidido mantener el anonimato de la misma y de su familia debido a las cuestiones y prácticas tan sensibles que se le atribuyen en este texto.
Tomando como partida la clasificación que Gabriel Martínez (2015: 92-93) realiza sobre las referencias a brujas en comunidades andinas de Bolivia, pero sin entrar en valoraciones de la veracidad de los testimonios, en Coipasi me encontré con «relatos de brujería» o narraciones sobre supuestos hechos cuyos protagonistas humanos y no humanos no estaban claros $^{4}$. Es decir, que tanto las personas que aparecen en esas historias, como los lugares o los diferentes seres, no son conocidos para los coipaseños, más allá de "un primo» o "un vecino». Como Rosaleen Howard ha mostrado, la narrativa andina se construye dotando de protagonismo a todos los interlocutores, atribuyéndoles nombres, así como el habla (2020). De igual forma, los diferentes espacios o lugares se hacen reconocibles al incorporarlos a las historias, siendo protagonistas inequívocos del mundo andino, también con sus nombres y agentividad (Salas 2019; Mannheim 2020). Esto no se hace con fines de veracidad como argumenta Martínez (2015: 94), sino como modos de permitir la comunicación entre diferentes seres por medio del diálogo (Howard 2020) o de reconocer la materialidad (corporalidad) y agentividad social de los lugares (Salas 2019: 200201). Por otro lado, existen lo que Martínez llamó "hechos de brujería», donde sí se reconoce a los protagonistas y a los lugares. Son hechos sucedidos a un individuo o familia y que son conocidos por toda la comunidad. Y, por último, estaría lo que yo considero que son los "cuentos de brujería», y que tienen como protagonistas a seres, humanos y no humanos, con nombres y características reconocidas, pero que son ubicados en otros lugares y tienen una estructura reconocible en cualquier comunidad cercana. De estos últimos nos han dado ejemplos en la región varios trabajos (Howard-Malverde 1984; Gutiérrez 1988; Rivera 2006; Krögel 2010; Gil 2019), aunque yo en Coipasi apenas pude recoger un par de ellos. Sin duda, de los tres, estos eran los menos frecuentes.

Los relatos e historias que recogí presentan claras diferencias con los registrados por Martínez. En Coipasi no parecen estar destinados a inducir el miedo o el

4 En este trabajo no distingo entre brujos o brujas. Se utilizara uno u otro término indistintamente o, en su defecto, la palabra quechua que lo designa: layqa. Por otro lado, la distinción que aquí realizo entre «relatos», «hechos» y «cuentos» de brujería, está basada precisamente en la presentada por Gabriel Martínez en el texto citado (2015), pretendiendo, como se verá a lo largo del texto, una crítica a la misma. 
temor entre los oyentes, o al menos no en la mayoría de las ocasiones. Los escuché en todos los ámbitos que uno pueda imaginar: en la noche, en un pequeño grupo familiar; individualmente a plena luz del día; en grupos reducidos mientras preparábamos el agua para regar; en una comida cotidiana. Además, los narradores no adoptaban una actitud especial al contarlos, eso que Martínez llamó «el modo de narrar», destinado hacer «llegar lo espeluznante de la narración» (2015: 96). Por otra parte, salvo en el caso de lo que he denominado "cuentos de brujas», en el resto no se muestra nunca una persecución de las brujas ni tampoco la muerte de éstas. Sí el castigo con destierro o la reprimenda por parte de las autoridades. Pero nunca pasaba a mayores.

Me interesa aquí señalar como esta presencia de la brujería en Coipasi se debe a la normalización de las prácticas de estos especialistas rituales, los brujos o layqakuna. Sus modos de hacer no resultan extraños en la comunidad y se entienden como parte de la comprensión local de la relación entre seres 0 , por decirlo de otra forma, ayudan a entender qué es ser runa, gente ${ }^{5}$. Lo que Guillermo Salas ha denominado que es la subjetividad de los diferentes seres (2019), y cuya propuesta recuperaré al final. Creo que más allá de que en ciertos contextos sí estén destinados a infundir temor, en general, la brujería no juega un papel tan funcional y sí, en cambio, conceptual, pues la normalización por parte de los comunarios de sus modos, para nosotros extraños, son parte de lo que se puede entender como una ontología local ${ }^{6}$. Así, mediante una etnografía de las brujas y los brujos, me gustaría en primer lugar, definir las características de éstas y, por otra parte, aportar ciertos principios para una discusión sobre la noción del miedo en los Andes.

\section{SER BRUJO}

En Coipasi existen tres formas de convertirse en layqa: los curanderos, yatiris o jampiris, que se

5 El término quechua runa es usado en la comunidad para referirse a la «gente», es decir, ellos mismos. No obstante, runa es inclusivo, y en general se aplica a todo humano que cumple con las condiciones para serlo, como veremos posteriormente: tener un alma, un cuerpo (vestido) y la capacidad de hablar.

6 Por ontología entiendo aquí no únicamente la forma de articular la comprensión de los diferentes seres, sino también las relaciones que se establecen entre ellos. $\mathrm{Si}$ se prefiere, el lector puede sustituir el término por el de cosmología (Muñoz 2020a). entiende, como se ha señalado en la región (Rösing 2008a y 2008b; Fernández 2015 y 2019), conocen las artes de la brujería ${ }^{7}$. Pero no tienen por qué usarlas o, por lo menos, no habitualmente. Este es el caso de la mayor parte de los curanderos de la comunidad, pues se dice de ellos que, siendo buenos, conocen esas artes de brujería que solo utilizan para contrarrestar el poder de los brujos de verdad. Los enemigos de estos curanderos pueden acusarlos habitualmente de brujería, aunque no es algo que comparta el resto de la comunidad. Estos casos han sido excluidos de mi análisis, pues es de consideración común en la comunidad que los verdaderos brujos son aquellos que actúan en secreto y que niegan además su condición; están también aquellos que viniendo de una familia de brujos, como doña Dionisia, continúan con la tradición y, por último, nos encontramos con los casos de runas que en un momento decidieron pactar con el diablo para conseguir determinado poder ${ }^{8}$.

En este último caso, que se podrían enmarcar en lo que Gabriel Martínez llamó "relatos de brujería», como nos informa don Anastasio Huaranca que le contó en una ocasión un coipaseño, hay que seguir un complejo ritual en el cerro en búsqueda del diablo al que se va a pedir el poder:

"'Mirá, vos tienes que ir un cerrito". Como si fuera este cerro, no ve. "Yo voy por otro lado sin que me vea nadie, sin que me ve nadie. Voy, pensando en eso, pensando pa' pedir con el diablo, el poder". Entos dice "vas yendo, se abre solo una puerta (dice). Una puerta, entrás, primero vas a encontrar

7 Para estudios sobre la brujería en los Andes durante la colonia ver los trabajos de Estenssoro (2003) o Fernández (2011 y 2012). Rösing (2008a y 2008b) y Fernández (2015), por su parte, han puesto de relieve la capacidad ambigua de los especialistas rituales andinos contemporáneos que les hacen encontrarse más allá de las nociones del mal, del bien, del miedo o incluso de la de brujería.

8 Gerardo Fernández Juárez lo explica muy bien para el caso aymara (2019: 319): «Brujo se dice en aymara layqa. Un layqa renocido sin discusión como tal en cualquier comunidad del Altiplano que sólo entendiera de la provocación ritual del daño y el maleficio entre los comunarios, tendría serios problemas de convivencia y de integración en las actividades colectivas cotidianas de la comunidad; no podría entrar en el desempeño de la carrera de cargos públicos esenciales en el reconocimiento social de la persona ni sería demandado, ni él ni su familia, para concertar aynis, "faenas", ni siquiera para el dominio integrador y prestigioso del parentesco ritual o "compadrazgo". En estas condiciones estará condenado a dejar la comunidad o vivir completamente aislado». 
una virgen (me dice). Pero esa virgen pasás más adentro, más adentro, hasta el último, adentro. Entos a la virgen vas a escupir (dice). Vas a pasar pero vas a escupir. De ahí vas un poco más adentro, más adentro, ahí (dice) hay animales, grandes. Leones (dice). No te va hacer nada, vas a pasar nomás. Seguir namás, seguir namás. Más adentro, ya vas a ver un [...] víboras. Víboras vas a ver (dice). Vos seguir pasando, no vas a tener miedo (dice), no te va hacer nada. Más adentro, ya va haber comidas (dice). Comidas, vas a comer todo lo que usted quiera. Y más adentro, ya es una ciudad (dice). Una ciudad se abre, uuuuu. Ahí está coches corriendo por el otro lado, como en la ciudad, ¿no? Así. Entones, seguir pasando, seguir yendo. A lo último, ahí va a estar el diablo. Un diablo, bien vestido. Entonces, te enfrentás a él, tienes que pedirte, lo que usted quiera. Pedir y pedir. Te va a dar el poder (dice). Pero, una sola obra. Si quieres tener camión, camión. Si quieres tener coche [...] todo lo usted quiere, pero una sola. Después de ahí, salís, ya con pensamiento y esto y ya. Al momento, con el diablo ya, con satanás ya hay que pedir, pagar, pedir... dame una cosa, quiero esto [...] y así [...]" Así dice que hacen los brujos».

La brujería no se puede llevar a cabo sin la intervención directa del diablo (Fernández 2011 y 2017; Sax 2014; Fernández y Gil 2019). El diablo es el que da el poder, sea el que sea, especialmente aquel que se quiere usar para dañar. $Y$ es que es con el diablo con el que tienes que renovar tu compromiso cada cierto tiempo. En varias ocasiones me contaron de estas relaciones periódicas entre brujos y diablos. En términos generales se dice que los brujos tienen por costumbre levantarse a hurtadillas de sus camas para ir en secreto a reunirse con el diablo en mitad del cerro. Entre otras cosas porque el diablo les está molestando constantemente en la noche y no les deja dormir. Allí le realizan ofrendas varias, dialogan con él o incluso tienen sexo: "Y se acerca a la piedra, se baja el pantalón, el diablo sale [...] ise sacude! Muchos decían así. Esos brujos dicen que así trabajan» (Anastasio Huaranca) ${ }^{9}$.

9 En otra ocasión el mismo don Anastasio me dijo: «Me han contado así siempre los que han visto. Todos han visto. Sabían contar. Así son los brujitos que trabajan. Al Guillermo mismo había aparecido. Hay un estanque, en Kelaque decimos, ahí. Había ido muy temprano, a las 3 por ahí. Cuando había ido, había encontrado a otro brujito. Brujo que estaba parado. Entonces justo encuentra en estanque, el brujo estaba parado ahí. Solamente estaría esperando el diablo que venga y se lo lleve. Y dice, éste: "Ay hermanito. Bien has venido a esta hora. Mirar,
Todos estos modos de actuar del layqa están relacionados con qaqas (salientes), punkus (puertas) o diferentes fuentes de agua en los cerros. Estos elementos del paisaje andino son por definición espacios peligrosos, lugares sajras (Cruz 2006). Asociados o no a los brujos, estos lugares aparecen como espacios liminales de encuentro entre entidades, donde uno puede ser sorprendido por espíritus de diferentes tipos (Rivera 2005). Por tanto, la práctica de los brujos se ubica en un contexto reconocible. Por una parte, el cerro, sabiendo que en estos lugares donde se realizan la mayor parte de los rituales de los especialistas, sobre todo aquellos destinados hacer el mal. Por otro lado, como señala Gerardo Fernández Juárez, los promontorios rocosos, las qaqas y otras aperturas del cerro son especialmente valoradas para estas artes (2019).

Aunque, como ya he mencionado en otras ocasiones, en Coipasi los espacios sajras no se limitan exclusivamente al cerro, pudiendo estar en cualquier punto del territorio, incluso en el mismo pueblo (Muñoz 2011), es cierto, que el cerro es imbuido de un aura de misterio, pues es sin duda el espacio que escapa del control humano y, sobre todo, el considerado más allá de lo doméstico (Figura 1). El pueblo en Coipasi comprende lugares como las casas, las calles y las alejadas chacras (huertas). Es decir, el pueblo, y por extensión lo doméstico, es todo aquel espacio donde se realizan habitualmente actividades humanas. Hasta hace unas décadas aquí podríamos incluir algunas partes de los cerros cercanos, pues cuando el pueblo estaba muy poblado había la necesidad de tierras para cultivar que se arrancaban a las faldas de los cerros. Hoy en día en el pueblo hay tierras baldías y, por tanto, las primeras abandonadas fueron aquellas ubicadas en los cerros. Ya nadie cultiva en ellos y pocos son los que llevan a sus ovejas o cabras a pastar por allí. EI cerro se ha convertido así en el lugar de lo salvaje, allí donde se liberan las ataduras de lo doméstico y donde todo aparece fuera del orden humano. Remito aquí a la idea de Francisco Pazzarelli, de lo domestico y lo salvaje. Pazzarelli menciona que, en la puna jujeña, los pastores entiende que por

mirar. A mí me estaban por llevar (me ha dicho). A mí me estaban por llevar. Allá, aquel río, es una ciudad liiinda. Coches correando, así, así. Luz, bárbaro. Entonces, ahí me estaban por llevar. Ahora, me salvaste"». 


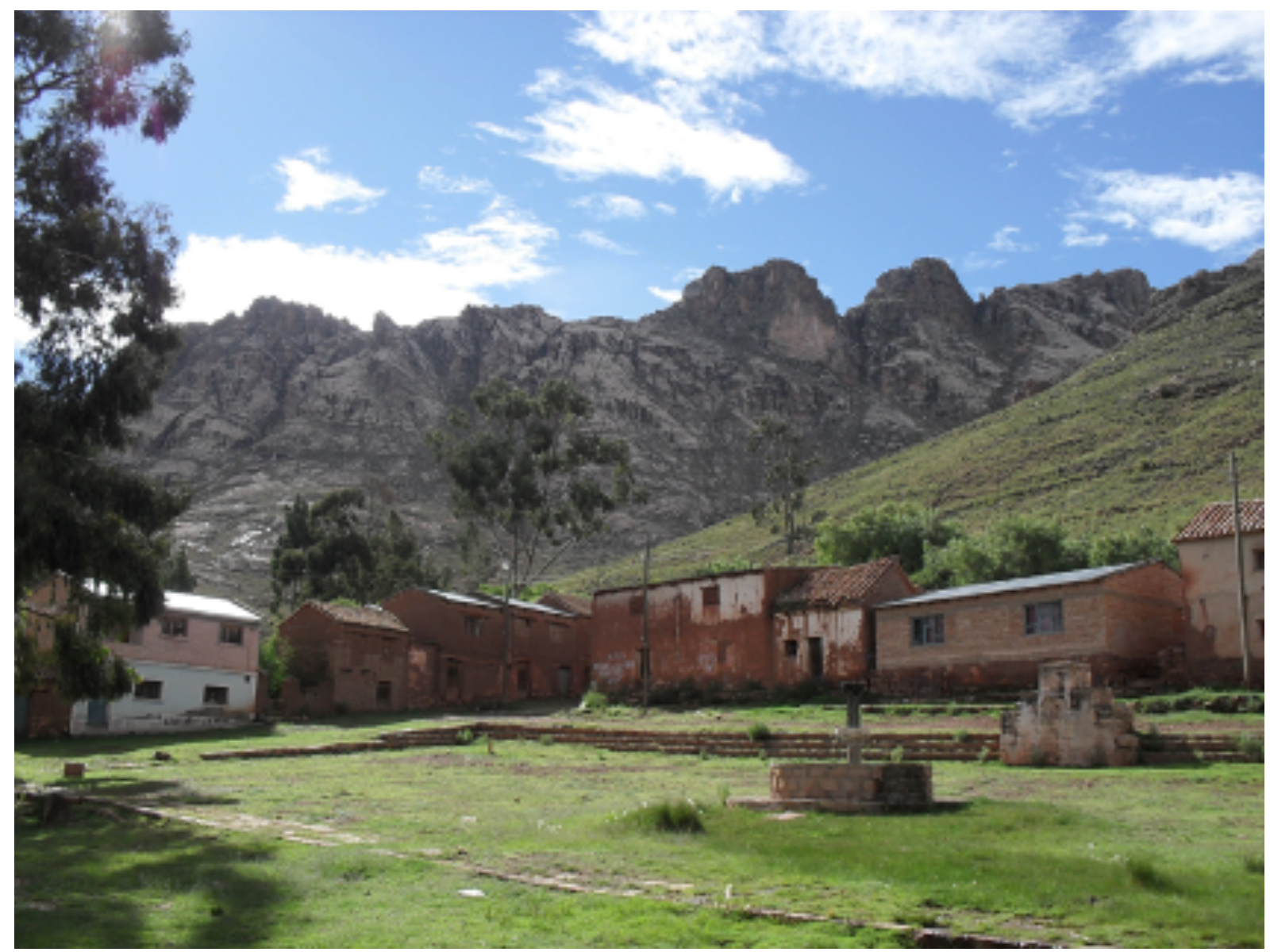

FIgURA 1. - La plaza de Coipasi y los cerros cercanos. Fotografía de Óscar Muñoz.

lo general todo, incluido el ánimo como principal esencia anímica de los humanos, tiende a ser salvaje, al exceso y sobrepasar el orden. La acción cotidiana de estos pastores está destinada a domesticar, controlar, este exceso tanto de los animales como de sus propias almas (2020). Peter Gose, en una crítica a las nociones que él denomina post-humanistas sobre los cerros en cuánto seres incluidos en las estructuras sociales humanas, menciona que la relación que los humanos establecen con éstos es más una cuestión de "estrategia» y no tanto "an inviolable cultural or ontological norm» (2018: 493). Gose defiende que las relaciones con los cerros en los Andes se construyen sobre los diferentes modos de domesticación y no tanto sobre percepciones que los consideran humanos o cómo humanos. Bajo esta perspectiva podemos entender, por tanto, que los brujos, entre otros, son los que pueden domesticar al cerro y su principal habitante, el diablo (ver p. ej. Absi 2005).
El cerro en Coipasi es también el lugar más apreciado por algunos malos espíritus para hacerse presentes ${ }^{10}$. De hecho, muchas de las conversaciones donde se hablaba de brujos, era común que se derivara hacía los encuentros con estos sajras espíritus, incluso identificándolos con brujos. El mismo Anastasio Huaranca menciona tras las palabras ya señaladas, que al brujo «también dice fantasma», y cuenta varias historias de espíritus aparecidos tanto en Coipasi como en otros lugares.

En otra ocasión, mientras ayudaba a dos amigos a «trancar agua», comenzaron hablar de doña Dionisia

10 Los malos espíritus o sajra espíritus, como ya he señalado en otro lugar (Muñoz 2020b), son aquellos en los que se convierten todas las almas de los muertos que no descansan y son condenadas. Son malos porque dañan a los humanos en sus encuentros y pueden presentarse casi bajo cualquier forma conocida. Para una noción parecida y también relacionada con la brujería, ver los encantos registrados por Marieka Sax en Kañari, norte de Perú (2019). 
y su familia ${ }^{11}$. Tras hacerle yo algunas preguntas sobre qué es lo que había pasado con ella, uno de ellos comenzó a contarme la historia de cómo él se asustó recientemente en el cerro ${ }^{12}$. En la historia, que conocí con detalle los días siguientes, ni él ni ningún otro miembro implicado (su mujer y el jampiri que lo trató) hicieron mención alguna a un embrujamiento. Según los tres, el hombre se asustó tras un encuentro con algún espíritu en el cerro durante la noche. Su error fue precisamente ese modo actuar, "como loco» decía el jampiri, pues remite a comportamientos no deseados como los de los brujos y corres el riesgo de encontrarte con los malos espíritus que pueblan estos paisajes durante la noche ${ }^{13}$.

Por tanto, como vemos, los modos en que los brujos adquieren su poder, pero, sobre todo, en como lo mantienen con relaciones con entidades, especialmente el diablo, y lugares sajras, es algo conocido en la comunidad, pues son muchas las personas que han tenido este tipo de encuentros en el cerro. Los brujos, por tanto, lo que hacen no es crear modos nuevos, sino provocar y perpetuar unas relaciones no extrañas, sino indeseadas por el común de los runas. Son peligrosos en cuanto consiguen incorporar al orden runa aquello que por naturaleza está fuera del mismo. Siguiendo la argumentación

11 «Trancar agua» es el término usado por los coipaseños para referirse a los turnos de riego. «Trancar» alude a la acción de cerrar los pozos o estanques de agua tras el uso reglamentario a fin de que los siguientes turnos puedan encontrar los depósitos llenos. Pero en realidad, cuando se dice "voy a trancar agua», se refiere a abrir el estanque, regar sus tierras y cerrarlo posteriormente. El buen hacer de estas acciones, como se supondrá, es fundamental para el mantenimiento no solo de las chacras, sino también del funcionamiento de la comunidad.

12 El susto o mancharisqa es la enfermedad más común en la comunidad. Se trata de una alteración del individuo después de que su esencia anímica, el ánimu, salga del cuerpo tras un susto o sobresalto repentino. Éste se puede dar por muchas razones y producir una alteración más leve, por ejemplo, un sonido estridente, o más graves, por ejemplo, el encuentro con un espíritu.

13 Es común escuchar a los coipaseños que los protagonistas de encuentros entre brujos y diablos (ya sea el propio brujo o el que los observa) se vuelvan «como locos» posteriormente. Nos dice Gerardo Fernández al respecto: "Las actuaciones dañinas de los "brujos" en los Andes potencian diferentes estados de alteración sistemática de la conciencia de sus víctimas que los lugareños suelen definir como "locura" o pérdida de juicio» (2017: 307). ya señalada de Gose, procesos conocidos de domesticación de los cerros y sus habitantes. De una forma similar, Marieka Sax argumenta que la cosmología kañari no se puede entender sin la presencia de los brujos que tienen, como principal objetivo, articular las relaciones con unos espíritus especiales denominados encantos (2014).

\section{HACER BRUJERÍA}

Son muy conocidas las formas rituales en como los brujos llevan a cabo sus deseos en los Andes. Se ha incidido especialmente en su carácter de especialista ritual, de sanador, y, por tanto, de las mesas negras, así como en la dificultad para distinguir la frontera entre el bien y mal (Rosing 2008a y 2008b; Fernández 2019). Tuve serias dificultades para acceder a este tipo de rituales en Coipasi, pues en todo momento los diferentes especialistas negaron el realizarlas o, tan siquiera, conocerlas.

Doña Dionisia, por ejemplo, durante toda nuestra conversación (esa que se perdió entre el hurto y el mundo digital) intentó convencerme de que no era una bruja como decían en la comunidad, sino una "curandera» y «naturalista» como reflejaban algunas credenciales que me mostró. Yendo y viniendo entre sus plantas medicinales, me dijo que procesaba especial devoción a San Jerónimo y a Tata Bombori, «a ellos le hago confiar» ${ }^{14}$.

Doña Dionisia aprendió de su papá, como ella misma me confesó, el cual también era tenido por brujo en la comunidad. En realidad, en Coipasi, la condición de layqa se extiende a toda la familia de doña Dionisia, pues en varias ocasiones me mencionaron que la bruja era su madre y no su padre. También en la actualidad se menciona que su hijo está aprendiendo a ser layqa. Doña Dionisia nació en la comunidad de Chajrosi y se fue a vivir al pueblo tras casarse con un coipaseño. En varias ocasiones, doña Dionisia fue acusada de brujería tanto en Coipasi como en las comunidades vecinas. Incluso me comentaron que fue desterrada de la comunidad en alguna ocasión

14 Las referencias a Tata Bombori o Santiago, santuario ubicado en el norte de Potosí, son constante en la región cuando de brujería se refiere (Platt 2019). Son muchos los especialistas rituales que procesan devoción a este santuario, uno de los más importantes del país, que también es usado para curar de brujería como veremos más adelante en el caso de don Macario. 
anterior hasta que, en 2015, tras la muerte de su marido, las autoridades le invitaron a regresar a Chajrosi de forma definitiva.

De doña Dionisia se dice que actuaba preferentemente de dos formas: dañando a la persona o personas elegidas mediante objetos diseñados expresamente para ellos; o mediante visitas a las casas de estas personas en forma de cabeza voladora. Estas dos formas son las más comentadas en la comunidad cuando se habla que alguien ha sido embrujado, se refieran o no a doña Dionisia.

\section{PELOS, ROPAS Y EXCREMENTOS}

Al menos en tres ocasiones me mencionaron como la forma más común de embrujar a alguien es enterrando en sus terrenos o en el cementerio una bola putrefacta hecha de cabellos, ropa y excrementos de la persona que se quiere embrujar (Fernández 2017: 297-298). Es decir, al layqa se le supone la cualidad de poder obtener cabellos, heces y prendas de estas personas sin que se den cuenta de ello. Además de poder luego enterrar en su propio terreno la bola que hacen con esos restos. Se supone que esta se va descomponiendo y pudriendo y es entonces cuando comienza hacer el mal sobre la persona o personas a las que va destinada.

Doña Miriam Mamani me decía que esto es muy importante saberlo, «por eso siempre me dijo mi mamá que nuestra ropa usadita no hay que votar al piso, hay que quemarla. Su cabello igual. No hay que dar. Así me dijo mi mamá».

Esta fue la forma en cómo fue embrujada su familia ascendiente por línea paterna. Nos dice don Macario, abuelo de doña Miriam, que comenzaron a sufrir muertes repentinas y desde un primer momento sospecharon que estaban embrujados. Gracias a un jampiri consiguieron localizar el embrujo: una bolita enterrada en un pozo en su terreno que tenía «todoooo, toda la clase de ropas, todas, cabellos, caca, todo. Había podrido» ${ }^{15}$. El culpable era un tío, hermano de su padre, que por medio de su mujer que era bruja, quiso acabar con toda la familia por una

15 En alguna ocasión me mencionaron que los brujos también pueden hacer el mal usando muñecos que imiten al embrujado, aunque no registré ningún «hecho» al respecto. Gabriel Martínez registró un caso donde uno de estos muñecos tenía en su interior excrementos y ropa (Martínez 2015: 96). cuestión de tierras. Pese a que descubrieron donde se encontraba el embrujo, no consiguieron evitar la desgracia familiar, incluso después de cambiarse de casa. Solo ha quedado vivo don Macario, y en malas condiciones, pues años después fue asustado por un hormiguero de chakas. Aunque un jampiri local y Tata Bombori consiguieron salvarle la vida, le dejó ciego de por vida ${ }^{16}$. El jampiri de este caso mencionó que don Macario fue asustado por un viento que se levantó en ese hormiguero. El mismo afectado afirma que ese viento todavía era consecuencia del embrujamiento familiar.

Doña Miriam, su nieta, nos pone en alerta sobre la peligrosidad de dejar nuestras ropas o cabellos, incluso heces, a merced de cualquier posible brujo. La pregunta que surge entonces es, ¿por qué específicamente estos elementos son tan apreciados por los brujos? Es evidente que hay una razón de posesión personal. Es decir, son cosas que pertenecen a la persona que se quiere dañar. Pero en la cosmología andina hay un elemento de continuidad y fluidez anímica que se antoja fundamental. Por decirlo de otra forma, no es importante que esos restos sean de la persona, lo que aprecia el brujo es que son la persona.

La literatura regional ha destacado en los últimos años la importancia de la fluidez para entender la relacionalidad entre seres (Bugallo 2016; Cruz 2016; Muñoz 2020a). En las muchas conversaciones que tenía con los coipaseños sobre la enfermedad y la muerte, aparecía frecuentemente el término ánimu. A mis preguntas sobre qué era el ánimu, remitían a qué es un ser vivo y en concreto qué es un runa. Este está formado por tres elementos: el ánimu, el espírito y el cuerpo. Las dos primeras son anímicas, la tercera es material y corporal. Todos hablan de la existencia del ánimu y coinciden en sus características, pues es considerada la principal de las tres, al ser la que confiere la personalidad, pero también la vitalidad de cada ser (Allen 1982; Taylor 1987; Lanata 2007; La Riva 2012). El cuerpo es compartido por todos los seres, aunque en principio cada uno posee uno diferente. El cuerpo humano se entiende como el contenedor de las dos esencias anímicas anteriores. Sin el cuerpo el humano no tiene sentido. Se percibe

16 Las chakas (de la familia de las Attini, pueden ser de dos tipos, o Atta-cortadoras de hojas- o Acromyrmexpodadoras-) son unas hormigas muy dañinas que devoran los cultivos. Son también tenidas por ser los malos espíritus. 
como un conjunto de envolturas sucesivas: se dice que el ánimu y/o el espírito (no está muy clara la distinción entre ellas) se aloja en el corazón (sonqo), que a su vez está protegido por los huesos, por el esqueleto. Éste a su vez está envuelto por la carne y la piel que, al mismo tiempo, en el caso de los humanos, está envuelto por la ropa. Nos dice Tomás Sequeli al respecto: «El espíritu es como este cuerpo, pelao. Y cuando le pongo ropa, pantalón a esta pierna, ya se ve como gente. Así también el espíritu ha formado con la carne. Esta carne se pudre, pero el espíritu nunca se pudre». Por tanto, la ropa no es simplemente algo que cubre el cuerpo, es una parte del mismo. Sin ella, el cuerpo no existe y, como consecuencia, el ser completo tampoco.

Por tanto, podemos apreciar que la piel, así como las uñas o el cabello, pero principalmente la ropa es una parte esencial de la comprensión del ser runa, gente, y no animal, espíritu o planta. La piel y la ropa, esencialmente ésta última, no es un mero elemento que cubre al ser, es parte del mismo e incluso donde parece alojarse el ánimu por fluidez y continuidad. Como han demostrado otras etnografías, en los Andes las prendas tienen tanta importancia en la formación de la persona entre otras cosas porque parecen adquirir atributos de ella (Allen 2015: 31) ${ }^{17}$. Catherine J. Allen ha afirmado que los Andes son un lugar definido por una animacidad compartida (2015: 24), donde los objetos no es que adquieran el ánimo de quien los genera (sean humanos o no humanos), sino que poseen este ánimo (Allen 2020). Es decir, es una suerte de fluidez o continuidad anímica (Bugallo 2020) entre seres, que comparten la misma esencia anímica ${ }^{18}$.

Como nos indica doña Miriam, no se puede dejar cabello o ropa por ahí tirada, pues es la misma persona la que se está dejando al alcance de los brujos. Por esta razón no se ponen a secar las prendas en lugares visibles y accesibles, únicamente en los patios interiores. También por eso, cuando se cava una nueva tumba en el cementerio, las prendas

17 Para discusiones parecidas sobre la importancia del ropaje para comprender a la persona ver a Pitarch (2017) o Raby (2019) para Mesoamérica; así como, principalmente, Viveiros de Castro (1998) para la Amazonía.

18 Respecto a si los objetos en los Andes adquieren agencialidad porque así se la atribuyen sus creadores o porque la poseen ellos al ser parte de su origen ver Muñoz (2020a). que aparecen de anteriores enterramientos no son tocadas con las manos y son introducidas con sumo cuidado y palos en la tierra. De igual forma, por eso el tajsi es muy importante tras el fallecimiento de las personas, pues lavar o quemar las prendas es una acción indispensable para liberarla del ánimu del difunto ${ }^{19}$.

\section{CABEZAS VOLADORAS}

Pero probablemente la técnica de los brujos que más asombra en la comunidad es la capacidad que estos tienen para desprenderse de la cabeza y conseguir que esta vuele hasta cualquier lugar, por mi lejano que sea (incluso comunidades de la región) para visitar las casas de aquellas personas que serán objeto del maleficio. La misma doña Miriam se pregunta cómo podrían hacerlo: «Pero, oye, yo pienso, grave pienso, ¿cómo se rompe su cabeza? ¿y su cuerpo qué hace en la cama? No, no sé yo. Yo pienso todo [...] ¿Con qué se corta o fricciona? No, no sé».

Las cabezas desprendidas del cuerpo, como elemento esencial de la cosmología andina, están presentes desde la época prehispánica. Las cabezas trofeo en culturas como Paracas, Nazca o Wari tenían un doble sentido: por un lado, el mismo ritual donde se producía un gran derramamiento de sangre, sirviendo ésta como ofrenda a la tierra y principio de la vida y la fertilidad (Proulx 2008; Bovisio y Costas 2012). Bovisio y Costas también ponen atención en que las cabezas mismas eran consideradas como seres vivos, ya que la vitalidad está asociada, como sucede en muchas de las culturas amerindias, con, precisamente, el cabello (2012); pero, por otro lado, sabemos que la cabeza se convertía en un contenedor de almas, que eran retenidas cerrando todos sus orificios. Las cabezas trofeo parece ser que eran, sobre todo, ofrendas destinadas a la fertilidad y productividad de la tierra, aunque si tenían esta capacidad era precisamente porque ellas en sí mismas eran cabezas vivas (Arnold y Hastorf 2008). Esto se debe a que la cabeza en los Andes es un punto esencial de entrada y salida de las fuerzas anímicas interiores. Se considera que al comienzo de la vida es por la fontanela por donde estas fuerzas anímicas

19 Por lo mismo, pude ver en varias ocasiones como el cabello que se cortaba era quemado o, en su defecto, enterrado, pero nunca se tiraba o se dejaba sin más en el suelo. 
pueden entrar $y$, de igual forma, en el momento final de la vida, por donde tienden a buscar el lugar de salida (Arnold y Hastorf 2008: 109 y ss).

Los brujos andinos, y en Coipasi no son una excepción, son capaces de desprender su cabeza (Ansión 1987: 146-149; Rivera 2006: 159; Martínez $2015)^{20}$. Esta aparece en la noche con un halo de luz, rodeada de pájaros que se caracterizan por ser muy ruidosos. Lo que resaltan todos los coipaseños es, sobre todo, la luz que acompaña a la cabeza, que incluso en ocasiones se identifica como una vela, pues esto permite verla sin problemas incluso a bastante distancia.

"Una vez claro, para el invierno, así para el San Pedro. Me trajeron pues a robar yacón. Entonces venía pues por aquí, estuve yendo yo allá, allá abajito estuve yendo ya. Justo allá abajo a la curva esa ha venido pues, luz. Apagando, brillando, apagando, brillando. Venía asicito nomás. Entonces justo he venido a su casa de su suegro, allá abajo ahí a la punta ha venido. Ahí estaba ardiendo: "paja, paja, pajar", así. Alumbraba, se apagaba, alumbraba, se apagaba. Entonces meta mirar de allá pues. "Chin, ¿qué es aquel?”, decía. Entonces de ahí otra vez ha caminado de, a la puerta de cementerio, otra vez ahí ha venido. Ya estuvo ya "¿dónde está la caja?", asicito ya estuve yo. Entonces de ahí ha mirado largo rato. Largo rato a mirar estuvo ahí también. Ya. Pero pájaros venían pues. En el medio pájaros. Pájaros: "iChaj, chaj, chaj, chaj, chaaaaj!”, están llorando. Entonces ya he venido, justo de ahí me ido yo. Y él también ha venido pues. Justo estaba entrando a la casa, y justo estaba entrando, por aquí quería pasar. Por aquí [por entre las piernas]. Entonces yo me he tirado pues a la puerta. Ha pasado por mi encima ha pasado. $Y$ arribita nomás del manantial. Ahí ha pasado. Entonces yo me he tirado adentro y entonces mi papá, “iCalejjjjjj!”, le he hecho gritar. Entonces, el frente era un hombre que se llamaba Simón Chijo [...]. Entonces ese había visto y entonces al rato ha venido y arribita de mi casa, vivía allá, ese rato han ido a ver allí, han ido a buscar, han ido a buscar. No había encontrado pues. Ahí era mujer» ${ }^{21}$

20 Recordemos que ya Gonzalo de Holguín en su diccionario de quechua apuntaba que Viss cocho o humapurik eran «Las brujas que dizen que las topauan de noche en figura de cabeça humana solamente situando assi viss viss» (2007: 230).

21 La onomatopeya chaj, chaj, chaj, o alguna muy parecida, aparece como una constante en todos los relatos recogidos en los Andes sobre las cabezas voladoras de brujas, como los presentados ya aquí por Gabriel Mar-
La presencia de la cabeza, por supuesto, no presagia nada bueno. Se sabe que se dirige a la casa de la persona destinataria del maleficio. Así, le sucedió a don Martin Sequeli hace muchos años. Tras ver una cabeza volando por los alrededores de su casa (dice que del papá de doña Dionisia) supo que le habían embrujado. En los siguientes meses su casa se cayó y su mujer enfermó hasta morir.

\section{MIEDO O SUBJETIVIDAD}

Pero en términos generales, los brujos, las brujas o las cabezas voladoras no infunden miedo a no ser que seas el destinatario de sus acciones. Don Marcial Sequeli en su testimonio así lo demuestra. Él no temía a la cabeza. Más bien se podría decir que infunden curiosidad, y no porque les resulte incomprensible que una cabeza pueda tener agencia independientemente de su cuerpo, sino más bien por cómo conseguirán los brujos desprenderse de ella y sobrevivir. A nadie parece extrañarle que una cabeza pueda volar sola en la noche y realizar acciones sobre los humanos. Lo que extraña, como muestra doña Miriam, es cómo harán los brujos para automutilarse ${ }^{22}$. Es decir, ella no se pregunta por la propia existencia de las cabezas o porqué éstas puedan tener agencia: trasladarse, moverse, tener vida, emitir sonidos y provocar enfermedades o males.

Como nos ha mostrado Viveiros de Castro, las formas corporales (el ropaje, "clothing») pueden ser variadas y para nada fijadas (1998). En gran parte de las culturas amerindias, y al menos en los Andes, no es necesario que el cuerpo aparezca completo para fungir como tal. El cuerpo es un receptáculo que envuelve y da vida a, para el caso andino, el ánimu. La cabeza, además, como órgano fundamental para entender el sentido de esta fuerza anímica y sus tránsitos fuera y dentro del cuerpo, ha sido en los Andes siempre un elemento especialmente significativo. La cabeza ha funcionado siempre como un cuerpo en sí.

Lo que quiero mostrar es que, al contrario de lo que pudiera parecer, estas cabezas voladoras, como

tínez y Juan Ansión. Este último indica que probablemente se refiere a una risa entrecortada por parte de las brujas (1987: 147). Sin tener los suficientes datos como para poderlo afirmar, yo más bien sugeriría que se entienden como formas del habla de estas cabezas.

22 Jacques Galinier ha señalado que la automutilación es uno de los elementos fundamentales entre los brujos otomíes de México (2019). 
fueron las cabezas trofeo en el pasado, no son entendidas en los Andes como seres extraños, sino más bien cercanos a los humanos. Como son las ñatitas hoy en día en La Paz o han sido los huesos chullpas de los habitantes del pasado primigenio ${ }^{23}$. Pero, sobre todo, como son los condenados, esos muertos que salen a las pocas horas de sus tumbas para vagar por el territorio local ya que sus almas han sido castigas por un mal comportamiento en vida. El cuerpo de los condenados se va descomponiendo y puede ser visto en ese estado, incluso faltándole algún miembro (Rojas 2013a y 2013b).

Las cabezas voladoras, como los condenados, ñatitas o huesos chullpas, demuestran, como dice Jacques Galinier para el caso de las brujas otomíes (2019: 377): «que no existe ninguna ipseidad del cuerpo humano [...] Las transformaciones de las 'brujas' señalan el carácter lábil del cuerpo humano, cuyos elementos se pueden asociar o disociar como en un rompecabezas».

Estas formas de reconocer a las brujas y los brujos, así como sus modos de hacer, no parecen producir temor entre los coipaseños. La brujería produce preocupación al embrujado, además de, claro está, sufrimiento. Pero al que simplemente observa, sin ser afectado, le produce más bien curiosidad $y$, tal vez, incertidumbre. Al menos en Coipasi, ese miedo, temor y horror del que nos hablara Gabriel Martínez, no se hace presente cuando de brujería se trata. Los coipaseños presentan formas de temor en otras narraciones que reflejan el encuentro con otros espíritus o entidades. Curiosamente este temor nunca se transmite como un sentimiento, y los coipaseños se preocupan especialmente por mostrar las consecuencias físicas de éste: cabellos de punta, pérdida de esfínteres, sensación de un cuerpo hinchado, ojos llorosos. Es decir, nunca escuché a nadie decir que tuviera miedo, aunque sí mostrar las consecuencias físicas de estos encuentros. Hay, de hecho, una expresión coipaseña que indica la actitud

23 Las ñatitas son calaveras a las que rinden culto diferentes hermandades en la ciudad de La Paz (Fernández 2010, Portugal 2017). Chullpa es el término usado en casi toda Bolivia para referirse tanto a los habitantes de un tiempo primigenio como a los restos, especialmente óseos, dejados por éstos. Se destaca de los restos chullpas su agentividad y capacidad de actuar casi como humanos (Muñoz 2014), así como de presentar características de cuerpos vivos como tener sangre en su interior (Casaverde 1970: 156; Ansión 1987: 91). ante la adversidad, y más concretamente la forma de combatir el miedo: «por mi capricho». Don Clemente Chijo, por ejemplo, ha vivido siempre junto a una de las barrancas donde más encuentros con malos espíritus se han producido (Figura 2). A mi pregunta de si no sentía miedo me contesta: «No, no tengo miedo. Más capricho me pongo. [Capricho es] Bueno, más coraje. Más coraje me pongo. Y así [...] me vengo nomás. Y por eso no me pasa nada, ni haberlo nada».

Es decir, según numerosos testimonios que he recogido en la comunidad, tener capricho o coraje es enfrentarse a la adversidad. Más concretamente, sacar a relucir una gran fuerza de voluntad para solucionar un contratiempo con fuerza y decisión. Aunque lo escuché en todos los contextos, como por ejemplo a la hora de afrontar disputas con otras comunidades o instituciones, era siempre usado por aquellos que describían que habían sobrevivido al encuentro con un mal espíritu. Por decirlo de otra forma, no existe el miedo porque existe el coraje o el capricho, que podríamos describir como la forma de saber actuar una vez que se reconoce con qué o quién se está enfrentando.

No obstante, es interesante que en todas las narraciones sobre brujería, no apareció ni las consecuencias físicas antes descritas, ni tampoco la expresión "por mi capricho» o alguna parecida. Por tanto, pareciera que "las "brujas" no remiten a fenómenos marginales, excéntricos» (Galinier 2019: 386).

El miedo se articula y construye socialmente con lo desconocido, lo extraño y lo imprevisible ${ }^{24}$. Guillermo Salas ha comentado que la lógica andina parece ser la inversa, subjetivar lo presente. Salas comenta como para que en los Andes un ser te asuste, es necesario reconocerlo como sujeto, «como una persona». Solo en estos casos uno puede entablar relaciones con él (2019: 131). Estando de acuerdo con esta propuesta, aunque no estando seguro de que subjetivar signifique siempre el reconocimiento como una persona, no creo que la subjetividad de, por ejemplo, las brujas o los brujos, tenga como consecuencia el temor o miedo, sino, simplemente,

24 La antropología del miedo generalmente se ha centrado en estos aspectos, es decir, en el análisis de aquello que genera los miedos colectivos (Fernández y Pedrosa 2008) o en el miedo como elemento propio del poder y la política (Boscoboinik 2016), pero en muy pocas ocasiones sobre el miedo como emoción y sentimiento individual. 


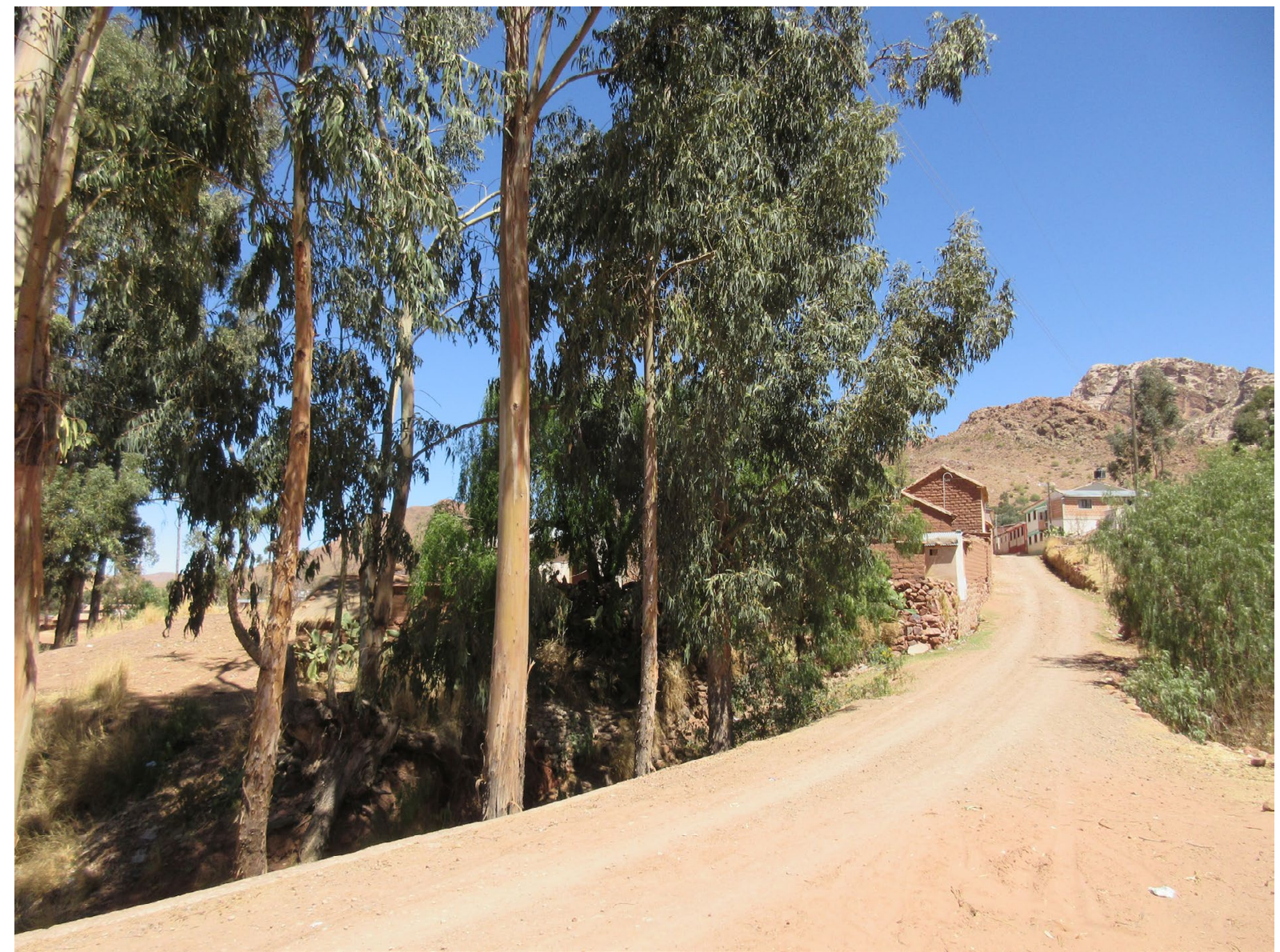

FIGURA 2. - Camino y barranca sajra en mitad del pueblo de Coipasi. Fotografía de Óscar Muñoz.

la relacionalidad. Lo que permite esta forma de hacer conocido lo supuestamente extraño, es relacionarse con él de una manera que a los coipaseños les resulta comprensible y accesible. Es decir, al contrario de lo que menciona Martínez, no hay cuestionamiento de la verdad del mundo de las brujas o los brujos. Este mundo simplemente existe $y$, en términos de Salas, se le subjetiviza, lo que permite relacionarse con él.

\section{CONCLUSIONES}

Brujos, brujas y brujerías están presentes en Coipasi. No resultan extraños y, por tanto, pasan a formar parte de la normalidad. El reconocimiento como sujetos de las brujas o sus muchas formas, de los seres con los que estas se relacionan, llámese diablo, cerro o fuente de agua y de sus modos de actuar, lleva al reconocimiento de la capacidad de relacionarse con ellas. Esto les permite a los coipaseños afrontar encuentros con cabezas voladoras, descubrir maleficios en sus terrenos o en los cementerios o toparse en el cerro con vecinos que están haciendo pactos con el diablo. Todo ello podría infundir al temor o, como hemos visto señala Gabriel Martínez, imaginar una serie de historias y relatos destinadas a fomentar el miedo. Pero como he pretendido mostrar, el miedo no entra dentro de las categorías reconocibles en Coipasi.

Los coipaseños no remiten nunca al miedo, por lo menos, no lo nombran. El miedo se refleja en sensaciones físicas que sólo se hacen presentes cuando se producen encuentros con diferentes espíritus. Estas sensaciones físicas, no son entendidas como miedo, o por lo menos los coipaseños no lo reconocen. Parecen funcionar más bien como una pérdida de control de la propia ontología, donde el espíritu provoca que el cuerpo humano deje de funcionar como se espera. Es entonces cuando los humanos deben sacar a relucir el capricho o el coraje, que es la capacidad de recuperar este control mediante dos ejercicios: la subjetividad de lo que se 
tiene enfrente; y una vez hecho esto, el saber actuar con fuerza para salir de ese trance.

Como ya he mencionado, este proceso nunca fue narrado con las brujas. Por tanto, en este texto he pretendido, por un lado, poner en cuestión el que las brujas sean un elemento de temor en Coipasi. Coincido con los argumentos ya señalados aquí por Gerardo Fernández y Ina Rösing en que gran parte de esto se debe a la ambigüedad propia de los especialistas rituales en los Andes. Pero también se debe a que las brujas no funcionan como seres extravagantes o misteriosos y, mucho menos, extraños. Por otro lado, gracias a esta percepción de las brujas he querido establecer unos principios a partir de los cuales discutir la noción de miedo en la región. Espero que estos primeros atisbos de discusión sobre esta emoción, ayude a otras investigaciones a definir las formas de relación entre seres en los Andes.

\section{BIBLIOGRAFÍA CITADA}

Absi, Pascale. 2005. Los ministros del diablo. El trabajo y sus representaciones en las minas de Potosí. La Paz: Instituto de Investigacion para el Desarrollo-Embajada de Francia en Bolivia-Instituto Francés de Estudios Andinos-Fundacion PIEB.

Allen, Catherine J. 1982. "Body and Soul in Quechua Thought». Journal of Latin American Lore 8(2): 179-196.

Allen, Catherine J. 2015. "The Whole World Is Watching: New Perspectives on Andean Animism». En Tamara L. Bray (ed.), The Archaeology of Wak'as. Explotarions of the Sacred in the Pre-Columbian Andes: 23-46. Boulder: University Press of Colorado.

Allen, Catherine J. 2020. «Inqaychus andinas y la animacidad de las piedras». En Óscar Muñoz Morán (coord.), Andes. Ensayos de etnografía teórica: 193-226. Madrid: NOLA Editores.

Ansión, Juan. 1987. Desde el rincón de los muertos. El pensamiento mítico en Ayacucho. Lima: Gredes.

Arnold, Denise Y. y Christine A. Hastorf. 2008. Heads of State. Icons, Power, and Politics in the Ancient and Modern Andes. California: Walnut Creek.

Bovisio, María A. y María P. Costas. 2012. «Cabezas trofeo: cuerpo, objeto y representación». En Actas del 1er Encuentro Latinoamericano de Investigadores sobre Cuerpos y Corporalidades en las Culturas. Facultad de Humanidades y Artes, Universidad Nacional de Rosario.

Boscoboinik, Andrea. 2016. «¿Por qué estudiar los miedos desde la antropología?». Arxiu d’Etnografia de Catalunya 16: 119-136.

Bugallo, Lucila. 2016. «Wak’as en la puna jujeña. Lo fluido y lo fino en el diálogo con pachamama». En Lucila Bugallo y Mario Vilca (comps.), Wak'as, diablos y muertos. Alteridades significantes en el mundo andino: 111-162. San Salvador de
Jujuy: Universidad Nacional de Jujuy-Instituto Francés de Estudios Andinos.

Bugallo, Lucila. 2020. «Pachamama y Coquena. Seres poderosos en los Andes del sur». En Óscar Muñoz Morán (coord.), Andes. Ensayos de etnografía teórica: 115-162. Madrid: NOLA Editores.

Casaverde Rojas, Juvenal. 1970. «El mundo sobrenatural en una comunidad». Allpanchis Phuturinqa II: 121-243.

Cruz, Pablo. 2006. "Mundos permeables y espacios peligrosos. Consideraciones acerca de punkus y qaqas en el paisaje altoandino de Potosí, Bolivia». Boletín del Museo Chileno de Arte Precolombino 11(2): 35-50.

Cruz, Pablo. 2016. "Pensando en Supay o desde el Diablo. Saqra, paisaje y memoria en el espacio surandino». En Lucila Bugallo y Mario Vilca (comps.), Wak'as, diablos y muertos. Alteridades significantes en el mundo andino: 171-200. San Salvador de Jujuy: Universidad Nacional de Jujuy-Instituto Francés de Estudios Andinos.

Estenssoro Fuchs, Juan Carlos. 2003. Del paganismo a la santidad. La incorporación de los indios del Perú al catolicismo: 15321750. Lima: Pontificia Universidad Católica del Perú-Instituto Francés de Estudios Andinos.

Fernández Juárez, Gerardo. 2010. "La revuelta de las "ñatitas": "Empoderamiento ritual" y ciclo de difuntos en la ciudad de La Paz (Bolivia)». Disparidades. Revista de Antropología 65(1): 185-214.

Fernández Juárez, Gerardo. 2011. Maleficios corporales. Posesión, hechicería y chamanismo en España y América (Siglos XVI-XXI). Quito: ABYA-YALA.

Fernández Juárez, Gerardo 2012. Hechiceros y ministros del diablo. Rituales, prácticas médicas y patrimonio inmaterial en los Andes (Siglos XVI-XXI). Quito: ABYA-YALA.

Fernández Juárez, Gerardo. 2015. «Diablo y ch'amakani: antropofagia simbólica y maleficio en el altiplano aymara de Bolivia». Chungara 47(1): 157-165.

Fernández Juárez, Gerardo. 2017. Brujería y aquelarres en el mundo hispánico. Una antropología de contrastes. Quito: ABYA-YALA.

Fernández Juárez, Gerardo. 2019. «Las tentaciones del diablo: 'Mesa negra' y maléfico en la cuenca del Titicaca». En Gerardo Fernández Juárez y Francisco M. Gil García (coords.), Sinestesias. Brujería y hechicería en el mundo hispánico: 283-330. Quito: ABYA-YALA.

Fernández Juárez, Gerardo y Francisco M. Gil García. 2019. "Las brujas a escena. A modo de presentación». En Gerardo Fernández Juárez y Francisco M. Gil García (coords.), Sinestesias. Brujería y hechicería en el mundo hispánico: 7-12. Quito: ABYA-YALA.

Fernández Juárez, Gerardo y José Manuel Pedrosa. 2008. Antropologías del miedo. Vampiros, sacamantecas, locos, enterrados vivos y otras pesadillas de la razón. Madrid: Calambur.

Galinier, Jacques. 2019. «Ontologías reversibles: las ‘brujas' y las formas elementales de la depredación entre los otomíes del México oriental». En Gerardo Fernández Juárez y Francisco 
M. Gil García (coords.), Sinestesias. Brujería y hechicería en el mundo hispánico: 365-390. Quito: ABYA-YALA.

Gil García, Francisco M. 2019. «Brujas, ogros y viceversa. La conjura del afuerino antisocial en los Andes». En Gerardo Fernández Juárez y Francisco M. Gil García (coords.), Sinestesias. Brujería y hechicería en el mundo hispánico: 503-533. Quito: ABYA-YALA.

Gose, Peter. 2018. «The Semi-Social Mountain. Metapersonhood and Political Ontology in the Andes». HAU: Journal of Ethnographic Theory 8 (3): 488-505.

Gutiérrez Estévez, Manuel. 1988. «Hipótesis y comentarios sobre la significación de la mama-huaca». En Manuel Gutiérrez Estévez (comp.), Mito y ritual en América: 286323. Madrid: Alhambra.

Holguín, Diego Gonzalo de. 2007 [1608]. Vocabvlario de la Lengva General de todo el Perv Ilamada Lengua Qquichua, o del Inca. Runasimipi Qespisqa Software.

Howard, Rosaleen. 2020. «Articulando perspectivas: el papel de la narración oral quechua en la construcción de la cosmovisión andina». En Óscar Muñoz Morán (coord.), Andes. Ensayos de Etnografía Teórica: 263-304. Madrid: NOLA Editores.

Howard-Malverde, Rosaleen. 1984. «Achkay: una tradición quechua del Alto Marañón». Chantiers Amerindia (3er. Trimestre). París.

Krögel, Alison. 2010. «Poderes de la narrativa oral quechua: Layqas, suq'as y "condenados"». Kipus, Revista Andina de Letras 28(2): 69-108.

La Riva, Palmira. 2012. Au plus près du corps: la construction sociale du corps-personne dans une communauté des Andes du sud du Pérou. Tesis de la Université Paris Ouest La Défense.

Lanata, Xavier Ricard .2007. Ladrones de sombra. El universo religioso de los pastores del Ausangate. Lima: IFEA-CBC.

Mannheim, Bruce. 2020. «Relatividad ontológica restringida». En Óscar Muñoz Morán (coord.), Andes. Ensayos de etnografía teórica: 47-84. Madrid: NOLA Editores.

Martínez Soto-Aguilar, Gabriel. 2015. «Sobre brujos y lik'ichiris: La creación cultural del horror». Boletín del Museo chileno de arte precolombino 20(1): 91-113.

Muñoz Morán, Óscar. 2011. «Imaginar el territorio atendiendo al pasado. Lugares, entidades y acontecimientos en México y Bolivia». Quaderni di Thule, XXXIII Convegno Internazionale di Americanistica XI: 87-95.

Muñoz Morán, Óscar. 2014. «Expresiones y manifestaciones chullpas. Una propuesta de explicación anímica». En Óscar Muñoz Morán y Francisco M. Gil García (coords.), Tiempo, espacio y entidades tutelares. Etnografías del pasado en América: 307-335. Quito: ABYA-YALA.

Muñoz Morán, Óscar. 2020a. «Introducción. Seres relacionales. Hacia una antropología de la fluidez desde los Andes». En Óscar Muñoz Morán (coord.), Andes. Ensayos de Etnografía Teórica: 7-46. Madrid: NOLA Editores.

Muñoz Morán, Óscar. 2020b. «Chullpasqa. Experiencias, emociones y espíritus andinos». En Óscar Muñoz Morán (coord.), Andes. Ensayos de Etnografía Teórica: 305-340. Madrid: NOLA Editores.
Pazzarelli, Francisco. 2020. «Parte-pastor. Notas sobre pastoreo y predación en los cerros jujeños (Andes meridionales, Argentina)». En Óscar Muñoz Morán (coord.), Andes. Ensayos de Etnografía Teórica: 85-114. Madrid: NOLA Editores.

Pitarch, Pedro. 2017. «A linha da dobra. Ensaio de cosmologia mesoamericana». Mana 24 (1): 131-160.

Platt, Tristan. 2019. «Seísmos de la mente. Un duelo chamánico en el Sucre de finales del siglo XX (Bolivia)». En Gerardo Fernández Juárez y Francisco M. Gil García (coords.), Sinestesias. Brujería y hechicería en el mundo hispánico: 431-458. Quito: ABYA-YALA.

Portugal Ramírez, Mario S. 2017. «La fiesta de las ñatitas reflexiones sobre la imagen del cuerpo-muerto como resistencia cultural». Repique. Revista de Ciencias Sociales 1: 106-117.

Proulx, Donald A. 2008. «Paracas and Nasca: Regional Cultures on the South Coast of Peru». En Helaine Silverman y William H. Isbell (eds.), The Handbook of South American Archaeology: 563-586. New York: Springer.

Raby, Dominique. 2019. "Calling through the water jar. Domestic objects in Nahua emotional assemblages». HAU: Journal of Ethnographic Theory 9(3): 529-544.

Rivera Andía, Juan Javier. 2005. "Territorio e identidad en los Andes. Concepciones populares en torno a las zonas ecológicas altas en la sierra de Lima». Revista de Dialectología y Tradiciones Populares 60(2): 55-76.

Rivera Andía, Juan Javier. 2006. «Mitología en los Andes». En Alejandro Ortiz Rescaniere (ed.), Mitologías amerindias: 129-176. Madrid: Trotta.

Rojas Zolezzi, Martha. 2013a. «El condenado y su necesaria expiación». En José Sánchez Paredes y Marco Curatola Petrocchi (eds.), Los rostros de la Tierra Encantada. Religión, evangelización y sincretismo en el Nuevo Mundo. Homenaje a Manuel Marzal: 145-162. Lima: IFEA-PUCP.

Rojas Zolezzi, Martha. 2013b. "La muerte del condenado». Tierra Nuestra 9(1): 55-70.

Rösing, Ina. 2008a. Defensa y perdición: la curación negra. Rituales nocturnos de curación en los Andes bolivianos. Madrid: Iberoamericana.

Rösing, Ina. 2008b. Cerrar el círculo: la curación gris como tránsito entre la negra y la blanca. Rituales nocturnos de curación en los Andes bolivianos. Madrid: Iberoamericana.

Salas Carreño, Guillermo. 2019. Lugares parientes. Comida, cohabitación y mundos andinos. Lima: Pontificia Universidad Católica del Perú.

Sax, Marieka. 2014. Sorcery and Morality in the Andes: IIIness, Healing, and Brujería in Kañaris (Lambayeque, Peru). Tesis doctoral. Carleton University, Ottawa, Ontario.

Taylor, Gerard. 1987. Ritos y Tradiciones de Huarochiri. Manuscrito quechua de comienzos del siglo XVII. Lima: Instituto de Estudios Peruanos-IFEA.

Viveiros de Castro, Eduardo. 1998. "Cosmological Deixis and Amerindian Perspectivism». Journal of the Royal Anthropological Institute 4(3): 469-488. 